\title{
Derechos Humanos y Democracia en el Vínculo Unión Europea - América Latina*
}

\section{Human Rights and Democracy in the Link European Union - Latin America}

\author{
Lorena Oyarzún Serrano** \\ Instituto de Asuntos Públicos \\ Universidad de Chile, Chile
}

Recibido: 6 de abril de 2017. Aprobado: 17 de enero de 2018.

\section{Resumen}

Este artículo analiza la relación Unión Europea (UE) - América Latina (AL), particularmente su vínculo con la democracia, los derechos humanos y se cuestiona si en el actual escenario continuará vigente este lazo. Se argumenta que si bien la relación ha sido valorada en las dos orillas, existen heterogeneidades. Ambas regiones en esta materia han ejercido un papel estratégico como hacedores de reglas en su definición, negociación e implementación. Sin embargo, enfrentan profundos desafíos: en la UE, la crisis humanitaria de los refugiados, los nacionalismos y el Brexit, mientras en América Latina, corrupción, inequidad y exclusión. Se sostiene que para mantener y fortalecer el lazo birregional se deben incluir temáticas escasamente abordadas, teniendo como guía la agenda 2030 y los Objetivos de Desarrollo Sostenible (ODS)

Este trabajo fue posible gracias a la beca CAF-CERI/Sciences Po para realizar una estancia de investigación en SciencesPo-París, Francia (2015). También al apoyo de la Fundación EU-LAC (2014) que permitió presentar una versión anterior del texto en el Congreso Internacional de FLACSO-Argentina / International Studies Association (ISA), "Regional and Global Powers in a Changing World", 23-24 de Julio de 2014, Buenos Aires, Argentina. La autora agradece los comentarios de José Antonio Sanahuja y los de los revisores anónimos de la revista.

** Académica del Instituto de Asuntos Públicos de la Universidad de Chile. Doctora en Relaciones Internacionales e Integración Europea de la Universidad Autónoma de Barcelona (UAB), España. Magíster en Derecho Internacional Público y Relaciones Internacionales (DEA) (UAB). Periodista y Licenciada en Comunicación Social de la Universidad de Chile. Email: loyarzus@iap.uchile.cl 
adoptados en las Naciones Unidas. Para desarrollar estas ideas, se utiliza el constructivismo y conceptos clave como regionalismo y actorness.

Palabras Clave: vínculo Unión Europea - América Latina, derechos humanos, democracia.

\begin{abstract}
This article analyzes the relationship between the European Union (EU) and Latin America (LA), especially concerning democracy and human rights, and explores whether their bond will be maintained. Although the relationship between the regions has been valued on both sides, there are heterogeneities. Both entities have played a strategic role as rule makers, but they face different challenges. The EU is facing humanitarian crises as a result of migration, the rise of nationalism and Brexit, while LA is fighting corruption, inequality and exclusion. I argue that in order to maintain and strengthen their connections, both regions should address the key issues highlighted in the 2030 Agenda and the Sustainable Development Goals (SDGs) adopted by United Nations. I develop these ideas using a constructivist perspective and key concepts such as regionalism and actorness.
\end{abstract}

Keywords: link European Union - Latin America, human rights, democracy.

\title{
Introducción
}

Uno de los activos de la relación Unión Europea (UE) - América Latina (AL) es el reconocimiento de principios y valores comunes, asociados con la promoción y defensa de la democracia, de los derechos humanos (DD.HH.), del multilateralismo y del desarrollo compartido. La democracia es definida como gobierno del pueblo; un concepto que se complejiza al vincularlo con la noción de ciudadanas y ciudadanos plenos, donde el Estado debería garantizar sus derechos políticos, sociales y culturales 
(PNUD, 2004). ${ }^{1}$ En tanto, la ciudadanía debe ejercerse en condiciones de libertad, igualdad y responsabilidad. Actualmente existe un amplio debate sobre la necesidad de promover una mayor participación de las personas en las decisiones que afectan sus vidas y de mejorar la democracia (Kaldor, 2012). En este sentido, la desigualdad y la vulneración de derechos son factores que influyen directamente en su calidad, dado que reflejan la asimetría del poder político y un Estado débil, muchas veces capturado por los intereses de las elites y sesgado en la aplicación de la ley a favor de esos grupos.

Para América Latina y la Unión Europea disminuir la inequidad es un desafío, pues "La vulneración de los derechos sociales fundamentales amenaza la igual dignidad y oportunidad de todos los seres humanos, constituyendo la igualdad la base misma de la democracia" (Mayor, 2013, p. 32). Al comparar ambas regiones, América Latina es 1,6 veces más desigual en promedio que la UE, siendo Uruguay el país menos desigual y Honduras el más desigual. En tanto, en Europa, Suecia es el menos desigual y los más desiguales son Portugal y Grecia (PNUD, 2014; CEPAL, 2015).

En el marco de Naciones Unidas, con la idea de disminuir la pobreza, la desigualdad, la injusticia, además de hacer frente al cambio climático e impulsar el desarrollo, los Estados miembros aprobaron en 2015, mediante la celebración de la Cumbre para el Desarrollo Sostenible, la Agenda 2030, incluyendo 17 Objetivos de Desarrollo Sostenible (ODS)2: 1) Fin a la pobreza; 2) Hambre cero; 3) Salud y bienestar; 4) Educación y calidad; 5) Igualdad de Género; 6) Agua limpia y saneamiento; 7) Energía asequible y no contaminante; 8) Trabajo decente y crecimiento económico; 9) Industria, innovación e infraestructura; 10) Reducción de las desigualdades; 11) Ciudades y comunidades sostenibles; 12) Producción y consumo responsables; 13) Acción por el clima; 14) Vida submarina; 15) Vida de ecosistemas terrestres; 16) Paz, justicia e instituciones sólidas y 17) Alianzas para lograr los objetivos.

Particularmente, la Comisión Económica para América Latina y el Caribe (CEPAL)

1 Para profundizar sobre el impacto de la globalización en la democracia y la ciudadanía véase Linklater (2007), Sojo (2002) y Held (1997).

2 Las negociaciones sobre la agenda para el desarrollo después de 2015 concluyeron con el documento "Transformar nuestro mundo: la Agenda 2030 para el Desarrollo Sostenible", que fue acordado por consenso por los miembros de Naciones Unidas. 
es la encargada de promover la implementación de los Objetivos de Desarrollo Sostenible en América Latina. En esta línea, advierte que los desafíos que enfrenta la región son estructurales: "escasa productividad y una infraestructura deficiente, segregación y rezagos en los servicios de educación y salud, persistentes brechas de género y desigualdades territoriales y con respecto a las minorías" (CEPAL, 2017, p. 7). La UE, por otra parte, ya cuenta con una estrategia para alcanzar los ODS. La Comisión Europea, por ejemplo, los abordó en la "Comunicación sobre los Próximos Pasos para un Futuro Sostenible de Europa" que vinculó las prioridades de la UE con la implementación de la Agenda 2030. También, en documentos como el "Consenso Europeo sobre Desarrollo” y "Una Asociación Renovada con los Países de África, El Caribe y el Pacífico". En ellos, expresan su compromiso para impulsar relaciones de cooperación con un enfoque de desarrollo sostenible, tanto dentro de la UE como en sus relaciones con actores externos (Comisión Europea, 2017a, 2017b, 2017c).

De particular interés para este estudio, son aquellos objetivos que abordan la gobernanza y la promoción de sociedades más pacíficas, justas y con instituciones fuertes (Objetivo 16) y los directamente relacionados con la inclusión como poner fin a la pobreza (Objetivo 1), lograr la igualdad entre los géneros (Objetivo 5), y reducir la desigualdad en y entre los países (Objetivo 10), pues son clave para impulsar la democracia y resguardar los derechos humanos. Si bien se reconoce la interconexión entre los ODS, se han enfatizado sólo algunos de ellos dado las constricciones de tiempo y espacio para el análisis.

Teniendo en consideración lo anterior y la cada vez mayor interdependencia entre las regiones, este artículo analiza la democracia y los DD.HH. en el vínculo UE$\mathrm{AL}$, particularmente se cuestiona si en el escenario actual este lazo continuará vigente. Se argumenta que si bien la relación ha sido valorada en las dos orillas, existen heterogeneidades. En Latinoamérica, los matices se manifiestan según los temas y los actores involucrados, a la vez que existen diferencias entre los países y organismos subregionales, en sus modelos de desarrollo y en sus percepciones sobre la democracia. La UE, por su parte, aunque mayormente institucionalizada como región y con una agenda europea sobre democracia y derechos humanos, presenta fracturas y contradicciones internas. Algunas de las cuales se observan en el tratamiento a los refugiados y en la gestión de la diversidad. De la misma forma, con 
el Brexit, proceso de desvinculación del Reino Unido de la UE, luego que la mayoría de los ciudadanos británicos votó en el referéndum de 2016. Por lo tanto, se sostiene que para fortalecer el lazo birregional es necesario incluir temáticas escasamente abordadas en la relación UE-AL, teniendo como guía la agenda 2030 y los Objetivos de Desarrollo Sostenible.

Para explicar las ideas planteadas, el texto se estructuró de la siguiente forma: en la primera sección se presenta el marco teórico y los conceptos clave. En la segunda sección, se discute la importancia de las ideas sobre democracia y los derechos humanos en la estructura jurídica y política de la Unión Europea. En la tercera sección, en tanto, se aborda la democracia y los DD.HH. en la cooperación UEAmérica Latina, destacando algunos vínculos de la Unión Europea con subregiones y países latinoamericanos. En la cuarta sección se exponen los desafíos que enfrentan ambas regiones con énfasis en la equidad de género, gestión de la diversidad cultural y el movimiento de personas. Finalmente, se presentan las conclusiones.

\section{Marco Teórico y Conceptos Clave: Constructivismo, Regionalismo y Actorness}

Con el fin de estudiar la democracia y los DD.HH. en el vínculo UE-AL y responder si este lazo continuará vigente en el escenario actual, se aplica un enfoque constructivista. El constructivismo como teoría analítica cuestiona la separación entre el sujeto cognoscente-objeto conocido y asume la realidad social como una permanente construcción. En esta línea, Price y Reus-Smit (1998) destacan la relevancia que otorga el constructivismo a las estructuras ideacionales, así como a las materiales; del mismo modo, el que las identidades son constitutivas de los intereses y de las acciones y que tanto la estructura como los agentes son mutuamente constituyentes. Al aplicarlo al estudio de la democracia y los derechos humanos en la relación UE-AL, se reconoce la capacidad de mutua constitución entre las estructuras y los agentes estudiados que, según el nivel de análisis, puede tratarse de la sociedad internacional, la región, el Estado e incluso los ciudadanos. Del mismo modo, otorga relevancia a la construcción de identidad e intereses (Adler, 2008; Barnett y Finnemore, 2004; Wendt, 1999). En este contexto, las ideas importan, pues 
tienen impacto sobre las políticas públicas y su efectiva implementación se convierte en un indicador de éxito o fracaso de esas políticas. Por lo tanto, el constructivismo como herramienta analítica resulta útil para estudiar la creación de regiones y sus vínculos para promover las ideas sobre la defensa de la democracia y los derechos humanos.

Por otra parte, se debe considerar que tanto en Europa como en Latinoamérica se han desarrollado diversos proyectos políticos en base a la región (regionalismo). La región, desde el constructivismo, se concibe como una entidad socialmente construida que podrá experimentar cambios a partir de sus interacciones internasexternas y transformar sus intereses e identidad. Los actores buscan administrar los desafíos económicos y de seguridad que provienen desde el exterior de la región (Hänggi, Roloff y Rüland, 2006). En las últimas décadas, las regiones han desplegado una mayor densidad de redes y lazos institucionales entre ellas, lo que se conoce como interregionalismo, proceso en el cual van profundizando y extendiendo sus interacciones políticas, económicas y sociales.

En tanto, actorness es un concepto asociado a la condición y poder del actor. También se relaciona a la personalidad legal y al derecho a participar e incurrir en obligaciones internacionales. A mayor actorness mayor capacidad de acción (Cmakalová y Rolenc, 2012). Analizar la actorness en el vínculo entre regiones resulta complejo, sobre todo cuando se trata de entidades heterogéneas en cuanto a su institucionalización, cohesión y reconocimiento externo, como es el caso entre la UE y AL.

En base a la tipología con enfoque constructivista propuesta por Barnett y Finnemore (2004) sobre organizaciones internacionales, la UE es una organización de integración con autoridad en su condición de burocracia, que crea reglas que delimitan el comportamiento. A su vez, cuenta con autoridad delegativa, pues sus Estados miembros le conceden tareas que ellos no pueden asumir. En el ámbito de los DD.HH., la UE ha demostrado un nivel de actorness que le ha permitido coordinarse a nivel interno y por lo mismo, actuar a nivel regional e internacional. En cambio, el caso de América Latina es distinto. Si bien las organizaciones regionales han incorporado en sus fuentes jurídicas el fortalecimiento y promoción 
a la democracia, así como también el respeto de los derechos humanos y el Estado de derecho como principios normativos, las competencias y atribuciones de los organismos latinoamericanos varían significativamente entre las organizaciones con personalidad jurídica y los foros de cooperación menos institucionalizados. Una manera de estudiar la solidez de la acción conjunta UE-AL es a través del análisis de sus agendas, visión compartida de valores y principios que estas regiones tengan o no (Bretherton y Vogler, 2006).

Al aplicar el enfoque ideacional-constructivista, también se considera la densidad de los vínculos entre quienes construyen reglas y quienes las adoptan. Por lo que a mayor interdependencia económica, política, social, transnacional y/o cultural, mayor será la influencia en el delineamiento e instauración de las reglas socializadas y promovidas por el hacedor de reglas (Domínguez, 2013). De esta forma, al abordar la democracia y los derechos humanos en clave interregionalista, es esencial considerar la capacidad de acción de los involucrados, pero al mismo tiempo, las lógicas de poder y la acción de actores externos en el vínculo (Sanahuja, 2013; Van Klaveren, 2011). En la siguiente sección se analizan las ideas sobre democracia y los derechos humanos presentes en la estructura jurídica y política de la Unión Europea. Asimismo, se presentan algunos de los temas que han generado fragmentación interna en la UE como el caso de los refugiados y el de los romaníes en Francia.

\section{Democracia y Derechos Humanos en la UE}

La democracia y los derechos humanos sustentan “(...) todos los aspectos de las políticas internas y externas de la Unión Europea. Los derechos humanos son normas jurídicas universalmente aplicables. La democracia es una aspiración universal" (Consejo de la Unión Europea, 2012). Entre los Estados miembros de la UE se observa una alta convergencia en este tema, cohesión que le permite fortalecer su capacidad de acción (actorness) para difundir y promover sus valores, crear reglas e influir en la construcción de la gobernanza global. ${ }^{3}$

Los mayores desacuerdos se han producido en temas relacionados con Israel en el Consejo de DD.HH. (Barbé, 2014). 
Mediante el Tratado de la Unión Europea (TUE) se establecen como valores fundamentales, la dignidad humana, la libertad, la democracia, la igualdad, el Estado de Derecho y el respeto de los derechos humanos, incluidos los de las personas pertenecientes a minorías (art. 2), entre otros. En su artículo 21, en tanto, se estipula que la acción exterior debe inspirarse en la democracia, el Estado de Derecho, la universalidad e indivisibilidad de los derechos humanos y de las libertades fundamentales, la dignidad humana, la igualdad y solidaridad (TUE, 1992). Por lo que la UE debe procurar vínculos con terceros países que compartan estos valores y se incorpora la cláusula de los DD.HH. (1995) que le permite a la UE suspender y/o finalizar un acuerdo en el caso de graves violaciones (Barbé, 2014).

Su fuerte dimensión normativa se entiende al revisar sus orígenes, un contexto de post guerra y post Holocausto, en el que los principales promotores de la UE desean impedir un nuevo conflicto armado, asegurar el bienestar y resguardar los derechos fundamentales a través de la construcción de un sistema multilateral que fomente la interdependencia (Kaldor, 2012). En 1950, se creó el Consejo de Europa y se adoptó la Convención Europea de Derechos Humanos (CEDH). Sin embargo, no fue hasta después de la ratificación del TUE, en 1993, que la UE institucionalmente promueve la protección de los DD.HH. (Barbé, 2014). Posteriormente, en el 2000, se proclamó la Carta de los Derechos Fundamentales de la Unión, incorporada al Tratado de Lisboa en 2009.

No obstante los avances, se advierte que las cláusulas de DD.HH. en el Tratado de Lisboa son menos consistentes a nivel interno, en comparación con las exigencias que la UE establece en su relación con otras regiones y países (Barbé, 2014). Esta incongruencia se constató, por ejemplo, el 2010, cuando el gobierno francés implementó la polémica expulsión de gitanos (romaníes) ${ }^{4}$, contraviniendo el derecho a la libre circulación de ciudadanos provenientes de Rumania y Bulgaria, países miembros de la Unión desde 2007. Con ocasión de estos hechos, diversas organizaciones de DD.HH. protestaron, tildando la medida de discriminatoria y atentatoria a los objetivos fundadores de la UE:

Francia no ha firmado el Convenio Marco Para la Protección de las Minorías Nacionales del Consejo de Europa (1995). 
La presunta conexión entre los romaníes y la delincuencia se reitera con frecuencia en el discurso de incitación al odio (...) Estos problemas no son una excusa para estigmatizar a todos los romaníes, la gran mayoría de los cuales no infringe la ley. Es un principio ético fundamental que no debería culparse a todo un grupo por aquello que hayan podido hacer algunos de sus miembros (Comisionado para los Derechos Humanos, Consejo de Europa, 2012, p. 4).

En esta misma línea, la crisis de los refugiados sirios a partir de la guerra civil iniciada el año 2011 es un desafío impostergable de la UE que debe leerse como una crisis de gobernanza. Se estima que 6,6 millones de sirios se han movilizado producto de la crisis en su país, los mayores receptores de refugiados han sido los países vecinos a Siria, Turquía con 2.715.789 refugiados, Líbano con 1.067.785 y Jordania con 639.704 (Carbajosa, 2016; Sanahuja, 2016). Uno de los puntos más polémicos ha sido la negociación de la Unión Europea con Turquía en 2016 con el fin de frenar el flujo migratorio en las costas griegas, acordando expulsar hacia Turquía cualquier nuevo inmigrante en suelo europeo, incluso sirios que se encuentran protegidos en su calidad refugiados. En contraparte, la UE aportaría 3 mil millones de euros al gobierno turco para gestionar la compleja situación, además de permitir a ciudadanos turcos viajar sin visado y la UE se compromete a avanzar en la adhesión de Turquía a la UE.

El efecto del acuerdo UE-Turquía no es retroactivo, por lo tanto, los refugiados aceptados como tales deberán ser reasentados en Europa. Sin embargo, Amnistía Internacional y el Alto Comisionado de Naciones Unidas para los Refugiados (ACNUR) han afirmado que devolver a los llamados migrantes económicos es una cosa, pero una muy distinta es incluir en esos retornos masivos a víctimas de guerra (Abellán, 2016). Para Sanahuja (2016) existe un evidente interés político en agrupar a migrantes y refugiados por igual, de manera que las autoridades han apuntado a reducir las estimaciones de las víctimas de guerra en necesidad de refugio y, de esta forma, rehuir del cumplimiento del derecho a protección internacional.

En esta misma línea, el gobierno húngaro en 2015 construyó una barrera fronteriza entre Hungría y Serbia con el argumento del lento actuar de la UE ante la crisis 
de "inmigrantes ilegales" que pudiesen ser considerados postulantes a refugiados de guerra (El Universo, 2015). Mientras, Dinamarca aprobó una ley que permite confiscar los bienes a refugiados con el objetivo de costear su estancia en el país y aumentó el plazo de reunificación de los familiares. Estas acciones han sido denunciadas por ACNUR, manifestando que se trata de una flagrante violación de la Convención Europea de Derechos Humanos, a la Convención de Naciones Unidas sobre derechos del niño y de la Convención sobre Refugiados de Naciones Unidas. La confiscación también es aplicada en Suiza y estados alemanes federados de Baviera y Baden-Württemberg (BBC, 2016; Rojas, 2015).

Como se ha podido advertir, si bien los derechos humanos se han convertido en la base normativa de la UE y rasgo definitorio de su identidad, lo que le significó en 2012 recibir el Premio Nobel de La Paz, actos como los mencionados anteriormente merman de manera significativa su credibilidad y revelan una política de doble rasero. En la siguiente sección, se estudia la democracia y los DD.HH. en la cooperación UE-América Latina, destacando los vínculos de la Unión Europea con subregiones y algunos países latinoamericanos (México, Brasil, Chile y Cuba).

\section{Democracia y Derechos Humanos en la Cooperación UE-AL}

En perspectiva histórica, Cienfuegos y Jovtis (2009) sitúan el vínculo UE-AL en la década de los sesenta, aunque los primeros acuerdos de cooperación comercial de la Comunidad Económica Europea (CEE) se suscriben con Argentina en 1971, con Uruguay en 1973, con Brasil en 1974 y con México en 1975. El interés europeo por cooperar en esta etapa se basó en la percepción de vulnerabilidad, a raíz de la crisis del petróleo de 1973 (Arenal, 2006). La democracia y los derechos humanos no fueron tema de los convenios. No obstante, con la adhesión de España y Portugal en 1986 a la CEE, América Latina comenzó a tener mayor presencia en la agenda europea, tendencia que se fortaleció en los noventa, cuando se puso fin a las dictaduras en casi toda la región, abriendo una ventana de oportunidades favorable a la institucionalización de las relaciones, promoción y defensa de los DD.HH. y de la democracia (Blanc, 2005). 
En 1990, la cláusula democrática fue introducida a solicitud de Argentina con la suscripción del Acuerdo Marco de Cooperación Comercial y Económica con la CEE, posteriormente, se ha repetido con los distintos países y subregiones latinoamericanas. A partir de 1999, se generó una asociación estratégica birregional, por medio de la celebración de Cumbres de Jefes de Estado y de Gobierno de los países de la UE-AL. De esta manera, en 2013 se celebró la primera cumbre entre la UE y la Comunidad de Estados Latinoamericanos y Caribeños (CELAC), instancia que reúne a 33 países de la región, en la cual se consideró profundizar el diálogo en áreas aún no reconocidas como prioritarias y que fortalecerían la democracia y los DD.HH.

En la actualidad y pese a la crisis económica-política que ha afectado durante los últimos años a la UE, se han mantenido los compromisos hacia los derechos humanos y la democracia (Youngs, 2013). En 2012, el Consejo de la UE adoptó un marco estratégico para los siguientes diez años, paralelamente a un plan de acción. Del mismo modo, el Instrumento Europeo para la Democracia y los Derechos Humanos, orientado a reforzar los derechos humanos y las libertades fundamentales en los países más amenazados, cuenta con presupuesto de 1.575 millones de euros para el periodo 2014-2020, mientras que el Instrumento Financiero de Cooperación al Desarrollo está dotado con 23.295 millones de euros para igual periodo (Consejo de la Unión Europea, 2012). La UE es uno de los grandes donantes del mundo en esta materia, promoviendo por medio de su política exterior sus valores. En la Tabla $\mathrm{N}^{\circ}$ 1 se observan los sectores a los que la UE destina la mayoría de sus recursos para el periodo 2014-2020 en América Latina:

TABLA 1

Fondos bilaterales UE a América Latina (2014-2020) para fortalecimiento democracia y protección de los DD.HH.

\begin{tabular}{|c|c|c|c|c|c|c|c|c|c|c|c|}
\hline & \multirow[b]{2}{*}{$\begin{array}{c}\text { Índice } \\
\text { GINI }\end{array}$} & \multirow[b]{2}{*}{$\begin{array}{c}\text { Fondo } \\
\text { Bilateral } \\
\text { UE } \\
2007- \\
2013 \\
(\mathrm{M} €)\end{array}$} & \multirow[b]{2}{*}{$\begin{array}{c}\text { Fondo } \\
\text { Bilateral } \\
\text { UE } \\
2014- \\
2020 \\
(\mathrm{M} €)\end{array}$} & \multirow[b]{2}{*}{$\begin{array}{l}\text { DDHH } \\
\text { y Co- } \\
\text { hesión } \\
\text { Social }\end{array}$} & \multirow[b]{2}{*}{$\begin{array}{l}\text { Democracia, } \\
\text { Fortalecimien- } \\
\text { to Institucio- } \\
\text { nal y Diálogo } \\
\text { Político }\end{array}$} & \multicolumn{6}{|c|}{ Otras Asignaciones de la UE } \\
\hline & & & & & & $\begin{array}{l}\text { Paz y } \\
\text { Segu- } \\
\text { ridad }\end{array}$ & $\begin{array}{l}\text { Edu- } \\
\text { cación, } \\
\text { Inclusión } \\
\text { Social e } \\
\text { Igualdad }\end{array}$ & $\begin{array}{c}\text { Ali- } \\
\text { mentos } \\
\text { y Agua }\end{array}$ & $\begin{array}{l}\text { Jus- } \\
\text { ticia }\end{array}$ & $\begin{array}{c}\text { Cambio } \\
\text { Climáti- } \\
\text { co }\end{array}$ & $\begin{array}{c}\text { Otros } \\
\text { (Empleo } \\
\text { y moder- } \\
\text { nización } \\
\text { econó- } \\
\text { mica) }\end{array}$ \\
\hline $\begin{array}{l}\text { Nica- } \\
\text { ragua }\end{array}$ & - & $214 \mathrm{M} €$ & $204 \mathrm{M}^{*}$ & 21 & & 20 & & & 14 & 11 & 34 \\
\hline $\begin{array}{c}\text { Salva- } \\
\text { dor }\end{array}$ & 40,9 & $121 \mathrm{M} €$ & $149 \mathrm{M} €^{*}$ & & & 34 & 12 & & 24 & 10 & \\
\hline
\end{tabular}




\begin{tabular}{|c|c|c|c|c|c|c|c|c|c|c|c|}
\hline $\begin{array}{c}\text { Guate- } \\
\text { mala }\end{array}$ & 55,3 & $135 \mathrm{M} €$ & $186 \mathrm{M}^{*}$ & 35 & 16 & 12 & 10 & 8 & & & 19 \\
\hline $\begin{array}{c}\text { Pana- } \\
\text { má }\end{array}$ & 51,9 & $38 \mathrm{M} €$ & $\begin{array}{c}\text { No } \\
\text { Asigna- } \\
\text { do }\end{array}$ & & & & & & & & \\
\hline $\begin{array}{l}\text { Hon- } \\
\text { duras }\end{array}$ & 56,4 & $223 \mathrm{M} €$ & $\begin{array}{c}235 \mathrm{M} \\
€^{*}\end{array}$ & 17 & 18 & 13 & & 9 & 10 & 17 & 6 \\
\hline $\begin{array}{c}\text { Costa } \\
\text { Rica }\end{array}$ & 50,5 & $34 \mathrm{M} €$ & $\begin{array}{c}\text { No } \\
\text { Asigna- } \\
\text { do }\end{array}$ & & & & & & & & \\
\hline $\begin{array}{l}\text { Bo- } \\
\text { livia }\end{array}$ & 49,1 & $249 \mathrm{M} €$ & $\begin{array}{l}281 \\
\mathrm{M} €\end{array}$ & & & 33 & & 41 & 26 & & \\
\hline $\begin{array}{c}\text { Ecua- } \\
\text { dor }\end{array}$ & 45,2 & $141 \mathrm{M} €$ & $67 \mathrm{M} €^{5}$ & & & 28 & 26 & & & & 46 \\
\hline Perú & 43,9 & $135 \mathrm{M} €$ & $66 \mathrm{M} €$ & & & & & & & & 100 \\
\hline $\begin{array}{l}\text { Uru- } \\
\text { guay }\end{array}$ & 37,9 & $36 \mathrm{M} €$ & $\begin{array}{c}\text { No } \\
\text { Asigna- } \\
\text { do }\end{array}$ & & & & & & & & \\
\hline $\begin{array}{c}\text { Argen- } \\
\text { tina }\end{array}$ & 47,5 & $65 \mathrm{M} €$ & $\begin{array}{c}\text { No } \\
\text { Asigna- } \\
\text { do }\end{array}$ & & & & & & & & \\
\hline Brasil & 54,8 & $50,8 \mathrm{M} €$ & $\begin{array}{c}\text { No } \\
\text { Asigna- } \\
\text { do }\end{array}$ & & & & & & & & \\
\hline $\begin{array}{l}\text { Para- } \\
\text { guay }\end{array}$ & 53,6 & - & $\begin{array}{l}168 \\
\mathrm{M} €\end{array}$ & & 13 & & 60 & & & & 27 \\
\hline $\begin{array}{l}\text { Mé- } \\
\text { xico }\end{array}$ & 49,1 & $40 \mathrm{M} €$ & $\begin{array}{c}\text { No } \\
\text { Asigna- } \\
\text { do }\end{array}$ & & & & & & & & \\
\hline Chile & 50,9 & $20,5 \mathrm{M} €$ & $\begin{array}{c}\text { No } \\
\text { Asigna- } \\
\text { do }\end{array}$ & & 72 & & & & & 28 & \\
\hline $\begin{array}{l}\text { Vene- } \\
\text { zuela }\end{array}$ & 40,7 & $40 \mathrm{M} €$ & $\begin{array}{c}\text { No } \\
\text { Asigna- } \\
\text { do }\end{array}$ & & & & & & & & \\
\hline Cuba & - & $20 \mathrm{M} €$ & $50 \mathrm{M} €$ & & & & & 50 & & 35 & 15 \\
\hline $\begin{array}{c}\text { Co- } \\
\text { lombia }\end{array}$ & 53,5 & $163 \mathrm{M} €$ & $67 \mathrm{M} €^{6}$ & & & 46 & & & 28 & & 26 \\
\hline
\end{tabular}

*Adherido al Fondo Sub-Regional de América Central (120 M €). Fuente: Elaboración propia en base a CEPAL (2013 y 2015), www.ec.europa.eu y www.eeas.europa.eu

$\begin{array}{ll}5 & \text { Periodo } 2014-2018 . \\ 6 & \text { Periodo } 2014-2017 .\end{array}$

131 Si Somos Americanos. Revista de Estudios Transfronterizos 


\section{a. Vínculos de la UE con Subregiones Latinoamericanas}

La UE ha aplicado una aproximación variable distinguiendo a los estados latinoamericanos en función de su renta; paralelamente ha mantenido relaciones con las subregiones percibidas como réplicas del propio modelo europeo de integración, entre ellas, la Comunidad de Estados Latinoamericanos y del Caribe, Centroamérica, el Mercado Común del Sur (MERCOSUR), la Unión de Naciones Suramericanas (UNASUR) y la Alianza del Pacífico (AP).

De esta manera, en la Segunda Cumbre CELAC-UE en 2015 se generaron algunas iniciativas, particularmente se buscó fomentar la seguridad ciudadana en Centro América y el Caribe. El énfasis dado consideró que una parte muy significativa de países latinoamericanos sufre de inseguridad ciudadana, siendo uno de los desafíos fundamentales para la gobernanza democrática. La violencia criminal no sólo tiene costes económicos, sino también para la democracia y los derechos ciudadanos al afectar las libertades individuales y dañar el tejido social (PNUD, 2013). Por ello, se estableció un Plan de Acción que contempla acciones prioritarias centradas en la prevención, reinserción y rehabilitación de los internos y la efectiva aplicación de la ley.

Por otra parte, los lazos de la UE con Centroamérica (Costa Rica, El Salvador, Guatemala, Honduras, Nicaragua y Panamá) se han desarrollado en base al Diálogo de San José iniciado en 1984. Desde ese entonces, las relaciones se han ampliado y se han diversificado. En 2012, por ejemplo, celebraron un Acuerdo de Asociación, siendo el primero que la UE suscribe entre regiones. En éste, se estipuló promover la defensa de la democracia, los derechos humanos y la lucha contra la desigualdad, entre otros. La UE fue una de las primeras organizaciones en aplicar condicionalidad negativa a Honduras en 2009, cuando se destituyó al presidente democráticamente electo del país, Manuel Zelaya. Además de retirar al embajador, paralizó la ayuda financiera que ascendía a 65,5 millones de euros, después de que fracasaran las negociaciones para reponer al presidente Zelaya. Del mismo modo, suspendió a Honduras de las negociaciones del Acuerdo hasta que se normalizaron las relaciones en 2010 con la celebración de nuevas elecciones presidenciales en el país (Domínguez, 2013). Recientemente, la UE participó como observador internacional en las elecciones 
presidenciales de 2017 en Honduras y lamentó el lento conteo de votos.

Con el MERCOSUR, compuesto por Argentina, Brasil, Paraguay, Uruguay y Venezuela, la UE mantiene vínculos desde 1992, casi desde el origen del MERCOSUR creado en 1991. En 1995 firmaron un Acuerdo Marco Interregional donde el diálogo político y los objetivos de ampliar el comercio y la cooperación económica se instauraron. Y si bien, hace más de 15 años (1999) iniciaron las negociaciones para implementar un Acuerdo de Asociación que incluya, además de la dimensión política y la cooperación, el libre comercio, todavía no se concreta por falta de consenso en un tema clave, las condiciones de acceso a los mercados.

A través de su historia, han coexistido ideas que en algunos momentos han promovido el mayor o menor vínculo UE-MERCOSUR, estas percepciones responden a factores externos y domésticos. En el 2012, por ejemplo, el Congreso de Paraguay destituyó por medio de un controvertido juicio político al presidente de la época, Fernando Lugo. Ante esta situación, MERCOSUR suspendió temporalmente a Paraguay, invocando la Cláusula Democrática. Igual acción implementó la Unión de Naciones Suramericanas (UNASUR), organización sudamericana que integra a los 12 países sudamericanos. Esta vez, en cambio, la UE tuvo una reacción más recatada en comparación al caso de Honduras; ya que, si bien suspendió sus negociaciones con el MERCOSUR hasta la realización de nuevas elecciones en Paraguay, mantuvo sus programas de apoyo y de cooperación en el país.

Con otro miembro del MERCOSUR, Venezuela, hoy suspendido de la organización sudamericana, la UE ha mostrado preocupación ante la grave crisis de gobernabilidad, agudizada por los bajos precios del petróleo, su principal fuente de ingresos y por las denuncias de persecución política por parte de los oponentes al régimen. Del mismo modo, la Unión Europea ha enfatizado la necesidad de implementar un calendario electoral, respetar la Asamblea Nacional, liberar los presos políticos y abrir un canal humanitario. No obstante, las actuales autoridades venezolanas tienen muy presente el apoyo de España en 2002, que en ese momento presidía la UE, al intento de golpe de Estado contra el presidente Hugo Chávez. Del mismo modo, se destaca el incidente protagonizado por el Ex Monarca Español en la XVII Cumbre Iberoamericana (2007), al dirigirse al presidente democráticamente electo 
de Venezuela y conminarlo a mantener silencio con un “¿Por qué no te callas?” (De Sousa Santos, 2007).

Recordemos que a partir de 1999, cuando llegó al poder el presidente Chávez, el país vivió importantes cambios. Entre ellos, la aprobación de una nueva Constitución (1999), la transformación de las condiciones materiales de sectores anteriormente excluidos por medio de la implementación de planes sociales para combatir el analfabetismo, la ampliación masiva del régimen de pensiones y de la cobertura médica primaria en todo el país. No obstante, el proyecto se encontró con una fuerte oposición que, sumado a la crisis económica, un nivel de inflación acumulada en 2016 de más del 270\% (Finanzas Digital, 2017), la escasez de alimento, de medicinas, de divisas, las denuncias de falta de libertad de expresión, de concentración del poder y de persecución política, han puesto al Gobierno del presidente Nicolás Maduro en una situación difícil de sostener. La UE no cuenta con un acuerdo con Venezuela, tampoco es el principal socio comercial, representando sólo el $8,9 \%$ del comercio total de Venezuela. No obstante, de 2007 a 2013 la UE dirigió el 50\% de todos sus fondos destinados a Venezuela al ítem buen gobierno, democracia y derechos humanos. Las organizaciones regionales como la CELAC, la UNASUR o MERCOSUR tampoco han logrado abordar la compleja situación de Venezuela, fundamentalmente por no existir consenso entre sus miembros.

Por otra parte, desde la creación de la Alianza del Pacífico, la UE ha mostrado un gran interés y disposición al diálogo con esta iniciativa regional formada por Chile, Colombia, México y Perú en 2012. La Alianza del Pacífico tiene una fuerte orientación hacia la promoción del comercio internacional y la apertura. En su conjunto, los cuatro países son la octava potencia económica y exportadora a nivel mundial, representan el 39\% del PIB de América Latina y el Caribe, concentran el $52 \%$ del comercio total y el $45 \%$ de la inversión extranjera directa de la región. Su población alcanza a 225 millones de personas y cuenta con 52 países en calidad de observadores, lo que demuestra el amplio interés que ha concitado en la sociedad internacional. Asimismo, Chile, Colombia, México y Perú tienen acuerdos vigentes con la Unión Europea y en el contexto actual, la relación de la UE-AP podría retomar un nuevo impulso, más aún en tiempos de incertidumbre económica y política, post Brexit y con la administración de Donald Trump en Estados Unidos (Oyarzún, 2017). 


\section{b. Relaciones Bilaterales: UE- México, UE-Brasil, UE-Chile y UE-Cuba}

La UE mantiene con México vínculos diplomáticos desde 1960, pero recién en 1997 firmaron una asociación económica, política y de colaboración. En tanto, el 2000 suscribieron un Acuerdo Global con el fin de fortalecer el diálogo político, el comercio y la cooperación. En los años subsecuentes al acuerdo, el comercio bilateral de bienes creció en un $140 \%$ y se institucionalizaron Consejos Conjuntos Ministeriales de carácter bianual para abordar temas relativos a problemáticas de crimen organizado transnacional y cambio climático. Adicionalmente, un Comité Conjunto de carácter anual aborda temáticas de cohesión social, DD.HH., ciencia, educación, desarrollo y comercio bilateral. Desde 2008, México es socio estratégico de la UE, siendo uno de los dos países en toda la región (EEAS-México, 2016).

Los desafíos de México son significativos, amplios sectores de la población se encuentran excluidos del progreso, con inseguridad y un serio problema de corrupción afecta el tejido político, económico y social. En esta línea, se inscribe la desaparición forzada de 43 estudiantes normalistas en Iguala (Estado de Guerrero, en México) en 2014, que involucró autoridades municipales, sicarios, policías y hasta el ejército, generando movilizaciones en todo el país. En 2015, Transparencia Internacional situó a México en el lugar 95 en corrupción de 167 países, el peor del ranking de los países de la Organización para la Cooperación Económica y Desarrollo (OCDE) y muy por debajo de sus principales socios y competidores económicos en América Latina, 72 posiciones por debajo de Chile y 11 lugares por debajo de Brasil (Transparencia Internacional, 2015).

Por otra parte, la UE mantiene una fluida relación con Brasil que se remonta a 1960, cuando se convirtió en el primer país sudamericano en reconocer la Comunidad Económica Europea. En 1985, recuperada la democracia brasilera y en pleno proceso de su consolidación, las relaciones bilaterales se densificaron hasta que en 1992 firmaron un Acuerdo Marco de Cooperación. Sin embargo, es en 2007 que la UE establece una Asociación Estratégica con Brasil destinada a promover, entre otras, la paz y seguridad, asociación económica y contacto con los ciudadanos (EEAS-Brasil, 2016). 
Los vínculos UE-Chile se pueden situar hacia 1964, cuando fue instalada en Santiago la Oficina de la Comunidad Europea para Latinoamérica. Desde ese entonces se ha establecido una activa relación bilateral, especialmente a partir de los años noventa con el restablecimiento de la democracia en el país, donde el respeto a la democracia, las libertades individuales y los derechos humanos fueron un eje articulador del relacionamiento, símbolo del poder civil de la UE y de su política exterior con terceros países, buscando influir a través de las ideas (Freres, 2000; Rogers, 2009). La evolución de la UE como de Chile, con ideas similares sobre el mundo y un alto grado de diálogo, influyó en el avance hacia una mayor asociatividad que se consagró el año 2002 con la firma del Acuerdo de Asociación Estratégica.

En la dimensión de cooperación reconocieron como prioridad los derechos fundamentales, el desarrollo social y económico y la protección del medio ambiente. En los programas financiados con fondos europeos destacan la incorporación de los beneficiarios directos y la promoción de aquellas políticas públicas que fortalecen la cohesión social y la innovación, pues la inequidad es uno de los graves problemas (EEAS-Chile, 2016). Chile mantiene el peor Índice Gini de los países de la OCDE y es uno de los más desiguales de América Latina (OECD, 2016).

Con Cuba, en cambio, las relaciones se han visto afectadas por el proceso de cambio político en la Isla. La UE es el primer destino de sus exportaciones y segundo socio comercial, después de Venezuela. Sus principales productos de exportación son minerales combustibles y oleosos, tabaco, azucares y bebestibles. Asimismo, la contraparte europea es el inversor más importante para el país caribeño, fundamentalmente en los sectores de turismo, construcción e industria ligera y agro. En esta misma línea, tiene fuerte incidencia en la cooperación. Para el periodo 20142020 se destinaron 50 millones de euros para fortalecer el desarrollo sostenible, la seguridad alimentaria, modernización, agricultura y medioambiente (EEAS-Cuba, 2016).

La política de la UE hacia Cuba está delineada por medio de la posición común adoptada por el Consejo Europeo en 1996. En éste se determinó que la UE debe promover un proceso de transición hacia la democracia y el respeto de los derechos humanos. En marzo de 2016, la Unión Europea y Cuba suscribieron el Acuerdo 
Bilateral de Diálogo Político y Cooperación que refleja el estrechamiento de sus vínculos y permite a la UE promover sus valores e intereses. El acuerdo contribuye al acompañamiento y la "actualización" de la economía y sociedad cubana, en términos de políticas públicas, administración tributaria, descentralización y comercio exterior. Adicionalmente el acuerdo promoverá el desarrollo sostenible y los derechos humanos en torno a un contexto global (EEAS-Cuba, 2016). En la siguiente sección, se presentan los desafíos que enfrentan ambas regiones, con énfasis en la equidad de género, gestión de la diversidad cultural y el movimiento de personas.

\section{Desafíos en Ambas Orillas}

Un gran desafío para América Latina tiene relación con implementar políticas públicas con enfoque de género, objetivo número 5 (equidad de género) en los Objetivos de Desarrollo Sostenible, especialmente cuando se trata de interrupción del embarazo. Sólo en Uruguay, desde 2012, existe aborto voluntario en centros públicos y con menos de 12 semanas de gestación. En contraste, seis países latinoamericanos, El Salvador, Haití, Honduras, Nicaragua y República Dominicana en Centroamérica y Surinam en Sudamérica, ostentan las más restrictivas legislaciones del mundo, penalizando la interrupción del embarazo, incluso en casos de violación, inviabilidad fetal o peligro de la vida de la madre.

Amnistía Internacional (2014) ha denunciado que en países como El Salvador la condena por interrumpir el embarazo puede alcanzar hasta 40 años de prisión, impulsando a las mujeres a actuar en la clandestinidad y recurrir a métodos extremadamente peligrosos, entre ellos, ingerir raticida o introducir objetos punzantes por el cuello del útero. En Honduras la situación es igualmente preocupante: se estima que se practican cerca de 3.350 abortos inseguros por año y éstos son castigados con penas que van desde los 3 a 10 años de cárcel. Por su parte, varias organizaciones civiles han solicitado que se despenalice el aborto terapéutico.

Recién en 2017, Chile legisló para despenalizar el aborto en tres causales: violación, riesgo vital de la madre e inviabilidad fetal. Los cambios sólo se lograron, después de un arduo debate en el Parlamento y del pronunciamiento del Tribunal Constitucional 
que finalmente resolvió aceptar la legalidad del proyecto de ley, luego que un grupo de 10 senadores de la derecha más conservadora del país tratara de impedir su promulgación. En general, el resto de los países en la región despenalizan el aborto en caso de violación, riesgo de la madre, incesto, malformaciones y/o inviabilidad fetal. No obstante, la gran mayoría no ha implementado ninguna de las recomendaciones emanadas de la Conferencia Internacional Sobre Población y Desarrollo de 1994 en El Cairo, ni de la Conferencia sobre La Mujer en Beijing (1995), relativas a los derechos sexuales y reproductivos de las mujeres. ${ }^{7}$

Otro reto en ambas regiones dice relación con la gestión de la migración en el vínculo UE-AL. El movimiento de personas, ya sea de carácter voluntario o forzado, es una tendencia que ha ido en aumento y se intensifica a medida que existe mayor globalización e interdependencia entre las distintas zonas del planeta. Según el informe de Naciones Unidas sobre Migraciones, el número de migrantes en el mundo crece rápidamente alcanzando los 244 millones en 2015 (ONU, 2016). Por su parte, los flujos de población latinoamericana hacia la UE son elevados, 19 millones en 2013 (IOM, 2013). La mayoría de los migrantes latinoamericanos se concentran en España, Portugal e Italia. Pese a esto, el tema recién comienza a abordarse en 2003, cuando se mencionó de manera general en los Acuerdos de Diálogo Político y Cooperación celebrados con Centroamérica y la Comunidad Andina, compuesta en ese entonces por Bolivia, Colombia, Ecuador, Perú y Venezuela. ${ }^{8}$ Posteriormente, en 2010, se convirtió en uno de los tópicos más sensibles de la negociación en el Acuerdo de Asociación UE-Centroamérica.

En la VI Cumbre Unión Europea - América Latina y el Caribe (ALC) (2010) se estableció como objetivo lograr un mayor conocimiento de las realidades de la migración y promover la protección de los derechos humanos, entre otros. Los principales Estados latinoamericanos fuente de migración están bajo el Reglamento 539/2001 y a sus nacionales se les exige visado para entrar en la UE. Al mismo tiempo, existe preocupación sobre el procedimiento de retorno que aplica la UE a los

7 En el marco de las Naciones Unidas, se han celebrado cuatro conferencias mundiales sobre la mujer, en Ciudad de México (1975), Copenhague (1980), Nairobi (1985) y Beijing (1995). Para mayor información sobre los acuerdos y agenda acordada visitar http://www.unwomen.org/es/how-we-work/ intergovernmental-support/world-conferences-on-women

8 Venezuela renunció a la Comunidad Andina el año 2006, e ingresó al Mercado Común del Sur en 2012. 
migrantes irregulares, ya que permite el internamiento y expulsión de menores no acompañados, aumenta el periodo de detención hasta 18 meses y restringe el ingreso a la UE por cinco años.

No obstante, se han producido algunos avances, en 2015, durante la II Cumbre UECELAC, Colombia y Perú firmaron exención de visados en los 26 países del espacio Schengen. Dicha iniciativa fue impulsada por el gobierno español en el 2013 y permite a sus ciudadanos permanecer hasta 90 días sin necesidad de tramitar una visa. Los países latinoamericanos que hasta ahora necesitan solicitar el visado Schengen son Bolivia, Cuba, Ecuador, Guyana, Haití, Jamaica y República Dominicana.

En esta misma línea se enmarca la gestión de la diversidad cultural. En el caso de Europa, receptora de grandes flujos de inmigración, los desafíos se refieren a promover el respeto a la diversidad dentro de sus fronteras, incentivando la inclusión, participación y enfoque de derechos humanos en las relaciones sociales. En América Latina, por su parte, los desafíos se refieren a valorar la riqueza cultural de sus pueblos originarios, correspondiente a cerca del 10\% de la población total, es decir 50 millones de personas. ${ }^{9} \mathrm{Si}$ bien los pueblos indígenas, después de un largo camino de lucha por sus reivindicaciones, han logrado que varios países latinoamericanos ratifiquen instrumentos internacionales clave para resguardar sus derechos, como el Convenio 169 de la Organización Internacional del Trabajo, aún persisten grandes asimetrías e inequidad (Cabrero, 2013), desigualdad acentuada para el colectivo de mujeres indígenas que sufre doble discriminación por género y etnia (CEPAL, 2013). Por ello, resulta esencial incluir este tema al diálogo bilateral y promover el cumplimiento de los ODS 1 (fin de la pobreza), 5 (equidad de género) y 10 (reducción de las desigualdades), a la vez que podría ser una línea de trabajo a desarrollar en ambas regiones, donde los latinoamericanos contribuirían con su pericia en interculturalidad, especialmente en los países que se han reconocido como plurinacionales.

En Bolivia representan el 60\% de sus habitantes, en Guatemala y en Perú son casi la mitad, mientras que en México llegan al 10\% del total de su población, 11 millones de indígenas (Cabrero, 2013). 


\section{Conclusiones}

A través de este estudio, se confirmó que un factor determinante en el vínculo Unión Europea- América Latina ha sido el reconocimiento de valores comunes, asociados con la promoción de la democracia, de los derechos humanos, del multilateralismo y la cooperación. De la misma manera, se observó que la asociación interregional ha sido reflejo de las ideas y de la voluntad, tanto en la Unión Europea como en América Latina por robustecer el multilateralismo y los principios asociados a la defensa de la democracia y los DD.HH. en ambas regiones y en la sociedad internacional, aunque con distintas capacidades de influencia. También se advirtió que si bien la relación ha sido valorada en las dos orillas, existen heterogeneidades.

Por otra parte, se constató que la UE aplica una aproximación variable según el nivel de desarrollo, interés y concordancia con sus contrapartes latinoamericanas. De esta forma, sostiene relaciones con agendas específicas según la subregión (Comunidad de Estados Latinoamericanos y del Caribe, Centroamérica, el Mercado Común del Sur, la Unión de Naciones Suramericanas y la Alianza del Pacífico). Al mismo tiempo, mantiene vínculos bilaterales con los estados latinoamericanos y desarrolla lazos estratégicos con países como México y Brasil.

Asimismo, se advierte que en Europa el desarrollo de la democracia y de los derechos humanos ha ido de la mano del fortalecimiento del proceso de integración europeo y de su institucionalidad comunitaria. La cual reconoce, por ejemplo, que la acción exterior de la UE debe basarse en los valores que le dan identidad interna, reconocimiento y prestigio en el exterior como son la defensa de la universalidad, indivisibilidad e interdependencia de los derechos humanos y la promoción de la democracia. Sin embargo, también se han evidenciado contradicciones en su accionar. Sus desafíos son variados, a nivel doméstico están relacionados con la migración, democracia, seguridad, respeto a la diversidad y la emergencia de agrupaciones xenófobas. A nivel externo, se requiere trascender las agendas nacionales con el fin de adoptar una consistente acción exterior que permita delinear las reglas para el mundo y aportar en la construcción de la gobernanza global.

En este contexto, la UE debe buscar consenso interno para mantener su actorness y ser 
coherente en la aplicación de dichos principios y no disminuir su credibilidad. Por su parte, los países de América Latina están en vías de profundizar sus democracias, para lo cual es indispensable abordar el desarrollo desde una perspectiva crítica, aplicar enfoque de derechos humanos, enfrentar desigualdades persistentes, especialmente aquellas que afectan a las mujeres y a los pueblos originarios, históricamente excluidos y discriminados.

Asegurar que el Estado y las organizaciones internacionales representen efectivamente los distintos intereses y el bien común es una de las tareas más apremiantes que tienen las sociedades latinoamericanas y europeas del siglo XXI. De la misma manera, es importante armonizar la convivencia y respeto de las diferencias, equidad de género y justicia social, porque no existe real libertad si hay discriminación, temor al hambre, inseguridad, falta de acceso a la educación y a una salud de calidad.

Por lo tanto, se concluye que para que se mantenga la democracia y los derechos humanos en el vínculo UE-AL, ambas regiones deben incorporar temas que preocupan y afectan a sus ciudadanos. No será posible profundizar su relación si no abordan temáticas como el respeto de las reglas, la corrupción, acceso a los mercados o la falta de libertad de expresión. De igual forma, deben abordar el movimiento de personas, la diversidad cultural, equidad de género, la protección a los recursos naturales y el cuidado del medioambiente. En esta línea, ambas regiones podrían basarse en la agenda 2030 y los Objetivos de Desarrollo Sostenible como hoja de ruta, ya que es un plan de acción a favor de las personas, el planeta y la prosperidad. Además, reconoce la interdependencia de las tres dimensiones, económica, social y ecológica, del desarrollo sostenible. Del mismo modo, enfatiza el papel de los marcos regionales y subregionales, la integración económica regional y la interconectividad para el desarrollo sostenible.

\section{Referencias}

Abellán, L. (8 de marzo de 2016). La UE acuerda expulsar a Turquía incluso a los sirios en suelo europeo. El País. Recuperado de http://internacional.elpais. com/internacional/2016/03/07/actualidad/1457352301_920991.html 
Adler, E. (2008). Constructivism and International Relations. En W. Carlsnaes, T. Risse y B. Simmons (Eds.), Handbook of International Relations (pp. 95118). London, Thousand Oaks, New Delhi: Sage Publications.

Amnistía Internacional. (2014). Al borde de la muerte. Violencia contra las mujeres y prohibición del aborto en El Salvador. Recuperado de https://www.amnesty. org/es/documents/amr29/003/2014/es/

Arenal, C. (2006). Democracia y Derechos Humanos en las Relaciones Unión Europea-América Latina. Revista Electrónica Iberoamericana-ALCUE. Recuperado de https://www.urjc.es/images/ceib/revista_electronica/ vol_1_2007_1/REIB_01_C_Del_Arenal.pdf

Barbé, E. (2014). La Unión Europea como Promotora de Derechos Humanos en Naciones Unidas. En E. Barbé (Directora), La Unión Europea en las Relaciones Internacionales (pp. 395-414). Madrid: Tecnos.

Barnett, M. y Finnemore, M. (2004). Rules for the world. International Organization and World Politics. Ithaca: Cornell University Press.

BBC. (26 de enero de 2016). En qué consiste y por qué es tan polémica la nueva ley de Dinamarca que permitirá confiscar los bienes de los refugiados. BBC Mundo. Recuperado de http://www.bbc.com/mundo/ noticias/2016/01/160126_dinamarca_refugiados_am

Blanc, A. (2005). Los tres pilares del Acuerdo de Asociación Chile-Unión Europea: diálogo político, cooperación y comercio. Estudios Internacionales, 38(151), 73-116.

Bretherton, C. y Vogler J. (2006). The European Union as a Global Actor. Nueva York: Routledge.

Cabrero, F. (Coordinador). (2013). Ciudadanía intercultural. Aportes desde la 
participación política de los pueblos indígenas en latinoamericana. Quito: PNUD.

Carbajosa, A. (31 de marzo de 2016). Radiografía de un fracaso. El País. Recuperado de http://internacional.elpais.com/internacional/2016/03/30/ actualidad/1459356258_581156.html

Carta de los Derechos Fundamentales de la Unión Europea. (2000). En Diario Oficial de las Comunidades Europeas (2000/C 364/01). Recuperado de http://www. europarl.europa.eu/charter/pdf/text_es.pdf

CEPAL. (2017). Agenda 2030 y los Objetivos de Desarrollo sostenible. Una oportunidad para américa Latina y El Caribe. Santiago: Naciones Unidas. Recuperado de https://www.cepal.org/es/publicaciones/40155-agenda2030-objetivos-desarrollo-sostenible-oportunidad-america-latina-caribe

CEPAL. (2015). La Unión Europea y América Latina y el Caribe ante la nueva coyuntura económica y social. https://repositorio.cepal.org/bitstream/handle/11362/38217/ S1500331e_s.pdf;jsessionid=365AD1DACE3A8ABF7D4E4214E5C61BD3?sequence=4

CEPAL. (2013). Mujeres indígenas en América Latina: dinámicas demográficas y sociales en el marco de los derechos humanos. Documentos de Proyecto. Recuperado de http://www.cepal.org/publicaciones/xml/8/51148/ MujeresindigenasenAmericaLatina.pdf

Cienfuegos, M. y Jovtis, I. (2009). Las negociaciones del Acuerdo de Asociación entre la Unión Europea y Centroamérica: estado actual y perspectivas. Revista Electrónica de Estudios Internacionales, 17, 1-24. Recuperado de http:// www.reei.org/index.php/revista/num17/articulos/negociaciones-acuerdoasociacion-entre-union-europea-centroamerica-estado-actual-perspectivas

Cmakalová, K. y Rolenc, J. (2012). Actorness and legitimacy of the European Union. Cooperation and Conflict, 47(2), 260-270. 
Comisión Europea. (2017a). Comunicación sobre los Próximos Pasos para un Futuro Sostenible de Europa. Recuperado de http://europa.eu/rapid/press-release_ MEMO-16-3886_en.htm

Comisión Europea. (2017b). Consenso Europeo sobre Desarrollo. Recuperado de http://europa.eu/rapid/press-release_MEMO-16-3884_en.htm

Comisión Europea. (2017c). Una Asociación Renovada con los Países de África, El Caribe y el Pacífico". Recuperado de http://europa.eu/rapid/press-release_ MEMO-16-3885_en.htm

Comisionado para los Derechos Humanos (Consejo de Europa). (2012). Los Derechos humanos de los romaníes y de las comunidades itinerantes en Europa. Extracto del Informe Completo. Recuperado de https://www.coe. int/t/commissioner/source/prems/RomaTravellersExtraits_ESP.pdf

Consejo de la Unión Europea. (2012). Derechos Humanos y Democracia: marco estratégico y plan de acción de la UE, 11855/12, Bruselas, 25 de junio de 2012. Recuperado de http://register.consilium.europa.eu/doc/srv?l=ES\&f=ST\%20 $11855 \% 202012 \% 20$ INIT

De Sousa Santos, B. (26 de noviembre de 2017). ¿Por qué no te callas? O la colonialidad del poder. Página/12. Recuperado de http://www.pagina12. com.ar/diario/contratapa/13-95271-2007-11-26.html

Domínguez, R. (2013). The limits and contributions of the EU to democracy in Latin America: The cases of Mexico, Venezuela and Honduras. En A. Boening, J. Kremer y A. Van Look (Eds.), Global Power Europe - Vol. 2 (pp.181-197). Heidelberg, New York, Dordrecht y London: Springer.

EEAS-Brasil. (2016). EU relations with Brazil. Recuperado de http://eeas.europa. eu/brazil/index_en.htm 
EEAS-Chile. (2016). Las relaciones políticas y económicas entre la UE y Chile. Recuperado de http://eeas.europa.eu/delegations/chile/eu_chile/political_ relations/index_es.htm

EEAS-Cuba. (2016). Las relaciones entre la UE y Cuba. Recuperado de http://eeas. europa.eu/cuba/index_en.htm

EEAS-México. (2016). Las relaciones políticas y económicas entre la UE y México. Recuperado de http://eeas.europa.eu/delegations/mexico/eu_mexico/ political_relations/political_relations_framework/index_es.htm

El Universo. (29 de agosto de 2015). Hungría anuncia haber terminado de levantar su barrera en frontera con Serbia. Recuperado de http://www.eluniverso. com/noticias/2015/08/29/nota/5091836/hungria-anuncia-haber-terminadolevantar-su-barrera-frontera-serbia

Finanzas Digital. (20 de abril de 2017). El BCV informó al FMI una inflación de 274\% en 2016". 2017. Recuperado de http://www.finanzasdigital.com/2017/04/ bcv-reporto-al-fmi-una-inflacion-274-2016/

Freres, C. (2000). The European Union as a Global Civilian Power: development cooperation in EU-Latin American Relations. Journal of Interamerican Studies and World Affairs, 42(2), 63-85.

Hänggi, H., Roloff. R. y Rüland, J. (Eds.) (2006). Interregionalism and International Relations. New York: Routledge.

Held, D. (1997). Democracia y orden global: del Estado moderno al gobierno cosmopolita. Madrid: Paidós.

IOM. (2013). Informe sobre las migraciones en el mundo 2013. Recuperado de http://publications.iom.int/bookstore/free/WMR2013_SP.pdf 
Kaldor, M. (2012). La UE como nuevo tipo de autoridad política: el ejemplo de la política de seguridad. Revista Cidob d'Affairs Internacionals, 100, 113-130.

Linklater, A. (2007). Critical theory and World politics. New York: Routledge.

Mayor, F. (2013). Fortalecer la democracia a escala personal y colectiva. En M. Mesa (Coordinadora), El reto de la Democracia en un mundo de Cambio: respuestas politicas y sociales, Anuario CEIPAZ 2013-2014 (pp. 21-37). Madrid: Fundación Cultura de Paz.

OECD. (2016). Income Distribution and Poverty. Recuperado de http://www.oecd. $\mathrm{org} /$ social/income-distribution-database.htm

ONU. (2016). International Migration Report 2015. Recuperado de http:// www.un.org/en/development/desa/population/migration/publications/ migrationreport/docs/MigrationReport2015_Highlights.pdf

Oyarzún, L. (2017). The Pacific Alliance and the Construction of a New Economic Regime? Lights and Shadows of the Renewal of Open Regionalism. En J. Briceño y I. Morales (Eds.), Post Hegemonic Regionalism in the Americas. Toward a Pacific-Atlantic Divide (pp.141-158). Nueva York y Londres: Routledge.

PNUD. (2014). Human Development Report 2014. Sustaining Human Progress: Reducing Vulnerabilities and Building Resilience. New York: PNUD. Recuperado de http://hdr.undp.org/en/content/human-developmentreport-2014

PNUD. (2013). Informe regional de desarrollo humano 2013-14. Seguridad ciudadana con rostro humano. Diagnóstico y propuestas para América Latina. Nueva York: PNUD. Recuperado de http://www.undp.org/content/ dam/rblac/img/IDH/IDH-AL\%20Informe\%20completo.pdf 
PNUD. (2004). La democracia en América Latina: hacia una democracia de ciudadanas y ciudadanos. Nueva York: PNUD. Recuperado de http://www2. ohchr.org/spanish/issues/democracy/costarica/docs/PNUD-seminario.pdf

Price, R. y Reus-Smit, C. (1998). Dangerous Liaisons? Critical International Theory and Constructivism. European Journal of International Relations, 4(3), 259294.

Rogers, J. (2009). From 'Civilian Power' to 'Global Power': Explicating the European Union's 'Grand Strategy' Through the Articulation of Discourse Theory. Journal of Common Market Studies, 47(4), 831-862.

Rojas, A. (22 de septiembre de 2015). Europa se salta sus propias leyes de asilo. El Mundo. Recuperado de http://www.elmundo.es/ internacional/2015/09/02/55e4836f22601d33488b4586.html

Sanahuja, J. (2016). La Unión Europea y la crisis de los refugiados: fallas de gobernanza, securitización y diplomacia de Chequera. En M. Mesa (Coord.), Retos Inaplazables en el Sistema Internacional, Anuario 2015-2016, (pp. 71-100). Madrid: Fundación Cultura de Paz. Recuperado de http://eprints. ucm.es/37328/1/3.SANAHUJA-Anuario\%20CEIPAZ15-16.pdf

Sanahuja, J. (2013). Hacia un nuevo marco de relaciones entre la Unión Europea y América Latina y el Caribe. Recuperado de https://eulacfoundation.org/es/ documentos/hacia-un-nuevo-marco-de-relaciones-entre-la-uni\%C3\%B3neuropea-y-am\%C3\%A9rica-latina-y-el-caribe

Sojo, C. (2002). La noción de ciudadanía en el debate Latinoamericano. Revista de la CEPAL, 76, 25-38. Recuperado de http://repositorio.cepal.org/bitstream/ handle/11362/10799/076025038_es.pdf?sequence=1\&isAllowed=y

Transparencia Internacional. (2015). Corruption Perceptions Index 2015. Recuperado de https://www.transparency.org/cpi2015 
European Communities Council. (1992). Treaty on European Union. Luxembourg: Office for Official Publications of the European Communities. Recuperado de https://europa.eu/european-union/sites/europaeu/files/docs/body/treaty_ on_european_union_en.pdf

Van Klaveren, A. (2011). América Latina y la Unión Europea: la necesidad de una relación madura. En D. Wolllard, G. Maihold y M. Mols (Eds.). La agenda internacional de América Latina: entre nuevas y viejas alianzas (pp. 6277). Buenos Aires: Nueva Sociedad, Fundación Friedrich Ebert, Stiftung Wissenschaft und Politik.

Wendt, A. (1999). Social Theory of International Politics. Cambridge: Cambridge University Press.

Youngs, R. (2013). Derechos Humanos y Democracia. En G. Grevi y D. Keohane (Eds.). Desafios para la política Exterior Europea en 2013 (pp. 23-30). Madrid: FRIDE. Recuperado de http://fride.org/descarga/Desafiospolitica exterior_europea_2013.pdf 